Sport Science: Jurnal Sain Olahraga dan Pendidikan Jasmani ISSN 114-562X (Cetak), ISSN XXXX-XXXX(Online)

http://sportscience.ppj.unp.ac.id/index.php/jss/index

\title{
Analisis Kemampuan Footwork Tenis Meja Mahasiswa UKO Tenis Veja Universitas Negeri Padang
}

\author{
Dessi Novita Sari \\ Fakultas Ilmu Keolahragaan, Universitas Negeri Padang, Indonesia. \\ E-mail: dessinovita10@fik.unp.ac.id
}

\begin{abstract}
Abstrak
Permasalahan dalam penelitian ini Masalah dala m penelitina ini adalah rendahnya prestasi UKO Tenis Meja UNP yang berkemungkinan disebabkan oleh rendahnya kemampuan footwork, tujuan penelitian ini adalah untuk mengetahui kemampuan footwork atlet tenis meja UKO UNP

Jenis penelitian ini adalah deskriptif dimana peneliti hanya ingin melihat keadaan sebenarnya di lapangan tentang kemampuan footwork mahasiswa UKO tenis meja UNP. Populasi dalam penelitian ini adalah mahasiswa UKO tenis meja UNP berjumlah 34 orang. Teknik pengambilan sampel menggunakan proportional random sampling, sehingga jumlah sampel berjumlah 11 orang. Untuk mendapatkan data tentang footwork mahasiswa UKO tenis meja instrument tes yaitu tes footwork tenis meja. Teknik analisis yang digunakan sesuai dengan jenis penelitian yaitu dengan menggunakan penghitungan persentase.

Berdasarkan pengukuran dan analisa maka diperoleh hasil penelitian sebagai berikut: Kemampuan footwork atlet Unit Kegiatan UNP berada pada kategori sedang dengan persentase sebesar $36.36 \%$

Kata kunci: footwork

Abstract

Problems in this study The problem in this research is the low achievement of UKO UNP Table Tennis which is likely caused by the low ability of footwork, the purpose of this study is to determine the footwork ability of UKO UNP table tennis athletes

This type of research is descriptive in which the researcher only wants to see the real situation in the field about the footwork ability of UKP UNP table tennis students. The population in this study were UKP students of UNP table tennis totaling 34 people. The sampling technique uses proportional random sampling, so the number of samples is 11 people. To get data about footwork of UKO student table tennis test instrument that is table tennis footwork test. The analysis technique used is according to the type of research that is by using percentage calculations.

Based on measurements and analysis, the results of the study are as follows: UNP Activity Unit athlete footwork ability is in the medium category with a percentage of $36.36 \%$
\end{abstract}

Keywords: footwork

\section{PENDAHULUAN}

Unit Kegiatan Olahraga (UKO) merupakan salah satu wadah yang menyelenggarakan pelaksanaan proses kegiatan olahraga yang berada di lingkungan universitas, salah satunya Unit Kegiatan Olahraga (UKO) Tenis Meja di Universitas Negeri Padang. Melihat dari prestasi yang selama ini diraih oleh UKO Tenis meja UNP masih jauh dari harapan yang berkemungkinan disebabkan oleh rendahnya kemampuan footwork, hal ini didukung dari data yang diperoleh oleh penulis dari pelatih UKO Tenis meja UNP.

Berdasarkan pengamatan dan wawancara penulis dengan beberapa orang anggota dan pelatih yang berada di Unit Kegiatan Olahraga (UKO), penulis memperoleh informasi bahwa 
Sport Science: Jurnal Sain Olahraga dan Pendidikan Jasmani ISSN 114-562X (Cetak), ISSN XXXX-XXXX(Online)

http://sportscience.ppj.unp.ac.id/index.php/jss/index

pelaksanaan proses kegiatan olahraga belum berjalan dengan maksimal ini dibuktikan dengan masih banyak anggota yang memiliki kesulitan dalam melakukan perpindahan gerak langkah kaki (footwork), sehingga tidak bisa melakukan pukulan dan gerakan dengan leluasa.

Menurut A.M. Bandi Utama, dkk (2004: 4), pada dasarnya bermain tenis meja adalah kemampuan menerapkan berbagai kemampuan dan keterampilan teknik, fisik, dan psikis dalam suatu permainan tenis meja. Sejalan dengan pendapat yang dikemukan oleh ahli di atas, bahwa Pelaksanaan unit kegiatan olahraga tenis meja dapat dipengaruhi oleh beberapa faktor diantaranya adalah kondisi fisik, teknik, sarana dan prasarana, pelatih, motivasi, serta pengalaman.

Berdasarkan uraian di atas, maka penulis tertarik untuk mengadakan penelitian yang berkaitan dengan masalah tersebut di atas. Dari penelitian ini penulis berharap bisa membantu memberi solusi terhadap masalah footwork kerja kakiyang dialami oleh anggota Unit Kegiatan Olahraga (UKO) Tenis Meja di Universitas Negeri Padang.

Istilah footwork kerja kakisering didengar dalam beberapa cabang olahraga. Kemampuan footwork mempunyai peranan penting dalam permainan tenis meja karena laju bola yang sangat cepat dibutuhkan gerak kaki yang cepat dan tepat pula. Seorang pemain harus memperhitungkan kecepatan serta arah putaran bola. Pemain harus segera mengambil keputusan dengan cepat dan tepat agar mendapatkan keuntungan yang besar, tentu saja dapat mempermudah dalam meraih kemenangan dalam suatu pertandingan.

Permainan tenis meja bukan hanya masalah tangan saja, dari perkembangan teknik dapat dipahami untuk mencapai posisi yang maksimal harus ditunjang dengan sistem gerak langkah kaki yang makin sempurna, sehingga upaya untuk merebut kesempatan menyerang. Menurut A.M. Bandi Utama (2004: 2) Teknik dasar keterampilan permainan tenis meja antara lain: (1) Pegangan (grip), (2) Sikap atau posisi bermain (stance), (3) jenis-jenis pukulan (sroke), (4) kerja kaki (footwork). Dalam permainan tenis meja kemampuan koordinasi mempunyai peranan penting untuk dalam pembelajaran bagi para pemain tenis meja tingkat pemula sehingga dapat memukul bola secara akurat disertai dengan gerakan kaki yang tepat.

Menurut Alex Kertamanah (2003: 2) footwork adalah kemampuan menggerakkan langkah kaki untuk memukul serta melancarkan teknik kemahiran seseorang pada batas semaksimal mungkin atau melancarkan pukulan memutar, dalam posisi yang benar untuk mencapai pukulan pada timming yang tepat.

Menurut Hodges (2007: 56-57) mengungkapkan bahwa terdapat tiga dasar dari footwork, yaitu berat badan tetap berada pada bagian depan telapak kaki, bersiap untuk melompat, dan selalu bergerak ke kiri dan ke kanan setelah lawan mengembalikan pukulan namun tidak bergerak ke kanan dan ke kiri sebelum pukulan dilepaskan. Jadi pada dasarnya seorang pemain bergerak menempatkan diri sehingga ia dapat mengantisipasi bola yang datang dari lawan. Kecepatan bola yang datang dari lawan membuat pemain tenis meja harus bisa menguasai kemampuan footwork.

Menurut Achmad Damiri (1992:110), "Footwork kerja kakidalam permainan tenis meja pada garis besarnya dapat dibedakan untuk nomor tunggal atau nomor ganda". Adapun footwork dalam tenis meja dikenal dengan langkah satu, dua, tiga, dan lebih dari tiga. Langkah tersebut disesuaikan dengan titik bola yang datang, sesuai dengan jarak/ posisi pemain berdiri. Dalam permainan ganda ditemukan footwork berbentuk huruf, seperti huruf $\mathrm{T}$, $\mathrm{O}, \mathrm{V}, \mathrm{A}, \mathrm{N}$. Namun pada dasarnya footwork tersebut berasal dari langkah samping kiri kanan, dan langkah depan belakang, serong kiri dan kanan, serta berbentuk lingkaran. Antara pemain 
Sport Science: Jurnal Sain Olahraga dan Pendidikan Jasmani ISSN 114-562X (Cetak), ISSN XXXX-XXXX(Online)

http://sportscience.ppj.unp.ac.id/index.php/jss/index

yang satu dan lainnya bergantian menerıma bola kalau tıdak, maka poin untuk lawan. Dibutuhkan kerjasama antara pasangan dalam tim agar tidak salah komunikasi dan agar tidak bertabrakan dalam menerima bola. Jadi, dalam permainan tenis meja, mempunyai beragam bentuk atau pola langkah. Tugas pemain untuk menjaga keseimbangan agar bisa mengontrol dan mengendalikan tubuh, kemanapun arah bola datang agar bisa mengembalikan dengan sempurna bola ke arah lawan.

Menurut Alex Kertamanah (2003: 18), terdapat beberapa factor yang berpengaruh terhadap kecepatan footwork. Faktor-faktor tersebut antara lain:

1) Kesiapsiagaanya berposisi bagus, ini bermanfaat bagi kecepatan pergerakan langkah kaki termasuk kecepatan kembali posisi semula setelah pukulan pertama.

2) Antisipasi dan reaksi yang prima, ini merupakan modal utama dalam menciptakan gerak langkah kaki yang cepat dan tepat.

3) Besarnya tenaga atau kekuatan kedua kaki menepak lantai, sangat berpengaruh terhadap kecepatan pergerakan tubuh.

4) Pada saat pertukaran titik berat tubuh kelenturan kelincahannya pinggang mengandung manfaat yang penting. gerak langkah kaki yang tepat. Secara ekonomis akan mencapai tempat berposisi, kemudian baru melancarkan pukulan yang diharapkan.

Hal ini yang harus menjadi evaluasi bagi setiap pemain tenis meja, agar bisa melakukan footwork dengan benar. Sehingga kemanapun arah bola yang datang bisa diantisipasi dan menghasilkan angka untuk pemain. Hal yang perlu disadari, bahwa keterampilan untuk mampu mengontrol gerakan tidak biasa dikuasai dalam waktu yang relatif singkat (Dhiki, 2015: 23). Selain terus berlatih setiap hari, tidak ada cara lain untuk memperbaikinya. Dengan demikian perlu mengkaji ulang terus latihan teknik mengatur gerak kaki secara benar dan urut. Demi kemajuan teknik secara gemilang. Latihan yang benar, teratur, terukur, dan serius merupakan faktor yang sangat

\section{METODE}

Penelitian ini merupakan penelitian desrikptif dengan mengamati kemampuan footwork mahasiswa UKO tenis meja UNP.

\section{Subjek Penelitian}

Menurut Sugiyono (2012: 117) mengemukakan "Populasi adalah wilayah generalisasi yang terdiri atas obyek/subyek yang mempunyai kualitas dan karakteristik tertentu yang ditetapkan oleh peneliti untuk pelajari dan kemudian ditarik kesimpulannya". Populasi dalam penelitian ini adalah mahasiswa UKO tenis meja UNP berjumlah 34 orang. Menurut Sugiyono ( 2012: 81) mengemukakan sampel adalah bagian dari jumlah dan karakteristik yang dimiliki oleh populasi tersebut. Teknik pengambilan sampel menggunakan proportional random sampling, sehingga jumlah sampel berjumlah 11 orang.

\section{Instrumen Penelitian}

Untuk mendapatkan data tentang footwork mahasiswa UKO tenis meja instrument tes yaitu unjuk kerja footwork yang diukur menggunakan langkah ke arah 8 penjuru mata angin, dari Nike (2014: 40) dengan reliabilitas tes 0.982 dan validitas 0,961 .

Alat/ perlengkapan yang dibutuhkan adalah : 
Sport Science: Jurnal Sain Olahraga dan Pendidikan Jasmani ISSN 114-562X (Cetak), ISSN XXXX-XXXX(Online) http://sportscience.ppj.unp.ac.id/index.php/jss/index

1. Stopwatch

2. Formulir dan alat tulis

3. Kapur

4. Meteran

5. Patok 8 buah

6. Meja untuk bermain tenis meja

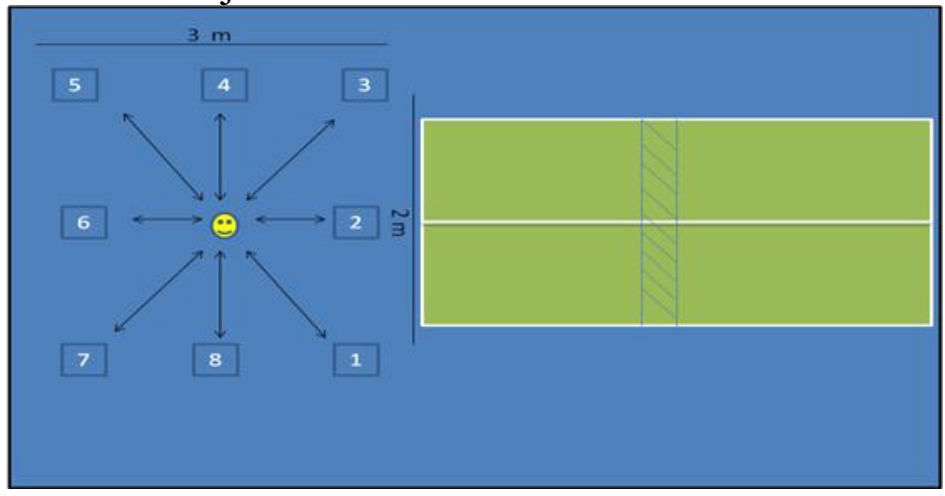

Gambar 1. Bentuk tes kelincahan Atlet tenis meja

Sumber (Nike; 2014)

\section{Pelaksanaan:}

1. Meja dibentang sebagaimana terlihat pada gambar

2. Pada lantai dibelakang meja dibuat garis membentuk kotak lebar 3 meter panjang 2 meter

3. Kemudian ditengah kotak yang telah dibuat tadi diberi tanda titik untuk menandakan posisi awal testee.

4. Patok disusun seperti yang terlihat digambar

5. Testee berdiri menghadap meja dengan posisi yang telah ditentukan, yaitu pada titik ditengah kotak

6. Setelah aba-aba "ya" stopwatch langsung dinyalakan dan testee mulai berlari kearah patok pertama kemudian balik ke posisi awal (ditengah) kemudian lanjut ke patok yang ke-2 begitu seterusnya hingga patok terakhir seperti gambar di atas, dan Testee akan berlari sesuai dengan arah yang telah ditentukan, lari ke patok pertama, balik ke posisi awal, kemudian lari ke patok ke-2 dan seterusnya. Ini dilakukan dengan secepatcepatnya selama 30 detik.

7. Penilaian: bila testee mencapai patok yang pertama berarti sudah mendapatkan hitungan 1, kembali lagi ke posisi tengah dan menuju patok ke-2 dihitung 2, dan begitu seterusnya. Bila kaki testee tidak sampai pada patok maka tidak dihitung. Hal ini dilakukan secara terus-menerus selama 30 detik. Pada akhir pelaksanaan nilai yang dicapai oleh testee kemudian dicocokkan pada daftar penilaian kelincahan.

\section{Teknik Analisis Data}

Sesuai dengan permasalahan dan tujuan penelitian deskriptif, maka data yang diperoleh akan disajikan dengan apa adanya yang berkenaan dengan faktor keadaan dan fenomena yang terjadi saat penilaian berlangsung dilapangan. Peneliti menggunakan teknik analisis dalam 
Sport Science: Jurnal Sain Olahraga dan Pendidikan Jasmani ISSN 114-562X (Cetak), ISSN XXXX-XXXX(Online)

http://sportscience.ppj.unp.ac.id/index.php/jss/index

mengolah data dengan menggunakan rumus persentase. Nasution (1996: 24) menyatakan "bila suatu penelitian bertujuan menggambarkan atau menemukan sesuatu sebagaimana adanya, maka teknik analisa yang dibutuhkan cukup dengan perhitungan persentase". Selanjutnya untuk panduan perhitungan persentase frekuensi jawaban dari penilaian ini menggunakan rumus :

$$
\mathrm{P}=\mathrm{f} / \mathrm{N} \times 100 \%
$$

Keterangan :

$\mathrm{P}=$ Tingkat persentase kemampuan

$\mathrm{f}=$ frekuensi

$\mathrm{N}=$ Jumlah sampel

\section{HASIL DAN PEMBAHASAN}

\section{Hasil Penelitian}

Pada bagian ini akan sajikan deskripsi data footwork tenis meja yang merupakan hasil pengukuran yang diberikan kepada mahasiswa UKO Tenis meja UNP menggunakan tes footwork dengan 8 penjuru mata angin.

Dari hasil pengukuran footwork yang dilakukan terhadap sampel mahasiswa UKO Tenis Meja UNP diperoleh skor tertinggi 22, skor terendah 16. Berdasarkan kemampuan footwork diperoleh nilai rata-rata hitung (mean) 18.91, nilai tengah (median) 19, dan simpangan baku (standard deviasi) sebesar 2.12. Untuk lebih jelasnya distribusi data footwork ini dapat dilihat pada tabel di bawah ini.

Tabel 1. Hasil Pengukuran Kemampuan Footwork

\begin{tabular}{|c|c|c|c|}
\hline Klasifikasi & Kelas Interval & $\mathbf{F a}$ & $\operatorname{Fr}(\%)$ \\
\hline Baik Sekali & $>22.09$ & 0 & 0.00 \\
\hline Baik & $19.97-22.08$ & 4 & 36.36 \\
\hline Sedang & $17.85-19.96$ & 4 & 36.36 \\
\hline Kurang & $15.73-17.84$ & 3 & 27.27 \\
\hline Kurang Sekali & $<15.72$ & 0 & 0.00 \\
\hline & Jumlah & 11 & 100 \\
\hline
\end{tabular}

Berdasarkan tabel frekwensi di atas dari 11 orang mahasiswa, ternyata tidak ada mahasiswa (0\%) memiliki Footwork dengan kelas interval berkisar dari $>22.09$ dengan kategori baik sekali, kemudian sebanyak 4 orang mahasiswa (36.36\%) memiliki Footwork dengan kelas interval berkisar dari 19.97 - 22.08 dengan kategori baik, lalu sebanyak 4 orang mahasiswa (36.36\%) memiliki Footwork dengan kelas interval berkisar dari 17.85 - 19.96 dengan kategori sedang, sedangkan sebanyak 3 orang mahasiswa (27.27\%) memiliki Footwork dengan kelas interval berkisar dari 15.73 - 17.84 dengan kategori kurang dan sebanyak 0 orang mahasiswa $(0 \%)$ memiliki Footwork dengan kelas interval berkisar dari < 
Sport Science: Jurnal Sain Olahraga dan Pendidikan Jasmani ISSN 114-562X (Cetak), ISSN XXXX-XXXX(Online)

http://sportscience.ppj.unp.ac.id/index.php/jss/index

15.72 dengan kategori kurang sekali. Hasil pengukuran tersebut kemudian disajikan ke dalam diagram batang sebagai berikut:

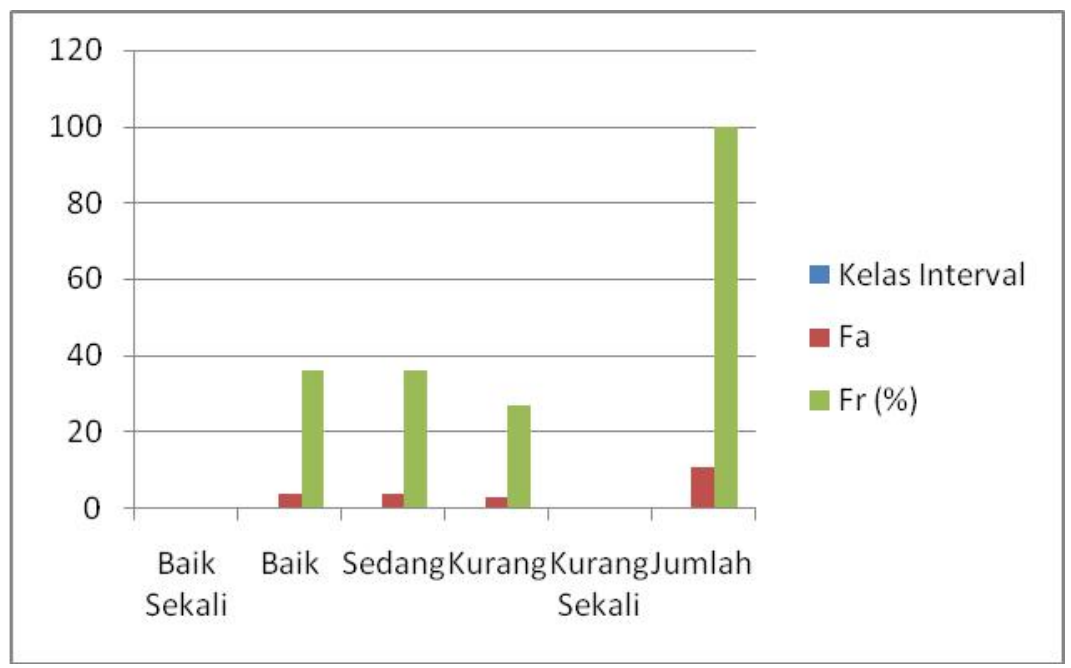

Grafik 1. Hasil Pengukuran Kemampuan Footwork

\section{Pembahasan}

Berdasarkan hasil penelitian yang telah diuraikan di atas maka dapat diketahui bahwa mahasiswa UKO tenis meja UNP memiliki kemampuan footwork pada kategori kurang sekali dengan persentase sebesar 0\%, pada kategori kurang dengan persentase sebesar $27.27 \%$, pada kategori sedang dengan persentase sebesar $36.36 \%$, pada kategori baik dengan persentase sebesar 36.36\%, pada kategori baik sekali dengan persentase sebesar 0\%. Melihat hasil temuan tersebut tentunya hal ini perlu mendapatkan perhatian yang serius dalam rangka mencapai prestasi. Dari kemampuan footwork dalam penelitian ini mempunyai nilai dan peran dalam memperoleh hasil terbaik dalam prestasi tenis meja. Menurut Alex Kertamanah (2003: 18), terdapat beberapa factor yang berpengaruh terhadap kecepatan footwork. Faktor-faktor tersebut antara lain:

5) Kesiapsiagaanya berposisi bagus, ini bermanfaat bagi kecepatan pergerakan langkah kaki termasuk kecepatan kembali posisi semula setelah pukulan pertama.

6) Antisipasi dan reaksi yang prima, ini merupakan modal utama dalam menciptakan gerak langkah kaki yang cepat dan tepat.

7) Besarnya tenaga atau kekuatan kedua kaki menepak lantai, sangat berpengaruh terhadap kecepatan pergerakan tubuh.

8) Pada saat pertukaran titik berat tubuh kelenturan kelincahannya pinggang mengandung manfaat yang penting. gerak langkah kaki yang tepat. Secara ekonomis akan mencapai tempat berposisi, kemudian baru melancarkan pukulan yang diharapkan.

Jadi pada dasarnya seorang pemain bergerak menempatkan diri sehingga ia dapat mengantisipasi bola yang datang dari lawan. Jika kemampuan footwork ini masih berada pada kategori rendah maka dikhawatirkan pemain akan mengalami kesulitan untuk melakukan permainan tenis meja, karena dibutuhkan keluwesan gerak setiap bola yang datang dari lawan. Footwork memiliki peranan penting dalam permaninan tenis meja karena permainan tenis meja dimainkan pada lapangan yang kecil dan permainan yang relatif cepat sehingga footwork 
Sport Science: Jurnal Sain Olahraga dan Pendidikan Jasmani ISSN 114-562X (Cetak), ISSN XXXX-XXXX(Online)

http://sportscience.ppj.unp.ac.id/index.php/jss/index

dapat menentukan keberhasilan dalam melakukan serangan dan dalam bertahan. Pengambilan keputusan seorang pemain dalam perpindahan tubuh ditentukan oleh tumpuan gerak kaki yang bisa berpindah dari satu titik ke titik yang lain dalam waktu yang singkat, sehingga akan memudahkan dalam mengembalikan bola dari lawan yang tidak bisa dtentukan dimana jatuhnya.

\section{KESIMPULAN}

Berdasarkan penjelasan pada bab sebelumnya maka dapat disimpulkan dalam penelitian ini adalah sebagai berikut: Mahasiswa UKO tenis meja UNP memiliki kemampuan footwork pada kategori sedang.

\section{DAFTAR RUJUKAN}

Hodges, Larry. (1996). Tenis Meja Tingkat Pemula. Jakarta: Raja Grafindo Persada.

Damiri, Ahmad dkk. (1991). Olahraga Pilihan Tenis Meja. Bandung: Depdikbud.

Kertamanah, Alex.(2003). Teknik dan Taktik Permainan Tenis Meja Dasar.

Bandung: Raja Grafindo Persada.

Sugiyono. (2012). Metode Penelitian Administrasi. Bandung: Alfabeta.

Yolanda, Nike. (2014). Pengaruh Latihan kelincahan terhadap kemampuan footwork atlet tenis meja Parak gadang. Skripsi. UNP: Padang.

Nasution, S.. (1996). Metode Penelitian Naturalistik-Kualitatif. Bandung: Tarsito.

A. M Bandi Utama dkk. (2004). Kemampuan Bermain Tenis Meja Studi Korelasi Antara Kelincahan dan Kemampuan Pukulan Dengan Kemampuan Bermain Tenis Meja. Laporan Penelitian Yogyakarta: FIK UNY

Alex Kertamanah. (2003). Teknik dan Taktik Dasar Permainan Tenis Meja.Jakarta: Raja Grafindo Persada.

Dhiki Agtri Dwi Santoso. (2015). Hubungan Pukulan Forehand Dan Footwork Terhadap Kemampuan Bermain Tenis Meja Pada Peserta Ekstrakurikuler Tenis Meja Madrasah Ibtidaiyah Negeri Tempel Sleman Yogyakarta. Skripsi. UNY: Yogyakarta. 